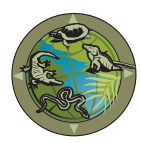

\title{
Observations of Australian Red-bellied Blacksnakes (Pseudechis porphyriacus) Preying on Freshwater Eels
}

\author{
Matthew Mo ${ }^{1}$, Peter Hayler ${ }^{2}$, and Antonia Hayler ${ }^{2}$
}

${ }^{1}$ P.O. Box A290, Sydney South, New South Wales 1232, Australia (matthew.sk.mo@gmail.com) ${ }^{2}$ Choosypix Photography, Oatley, New South Wales 2223, Australia (choosypix@yahoo.com.au)

Photographs by Peter and Antonia Hayler.

T The Red-bellied Blacksnake (Pseudechis porphyriacus) is a medium to large elapid of eastern Australia, commonly associated with moist areas (Wilson and Swan 2017). The species' diet is comprised primarily of frogs, but it also preys on small reptiles, birds, and mammals (Shine 1991; Cogger 2018). Some sources (Victorian Department of Environment,
Land, Water and Planning 2017; Australian Museum 2019; Queensland Museum 2019; University of Melbourne 2019) also list fish as a component of the diet; however, we are unaware of any published accounts of Red-bellied Blacksnakes hunting and catching fish. Herein we report two opportunistic observations of this species preying on freshwater eels.

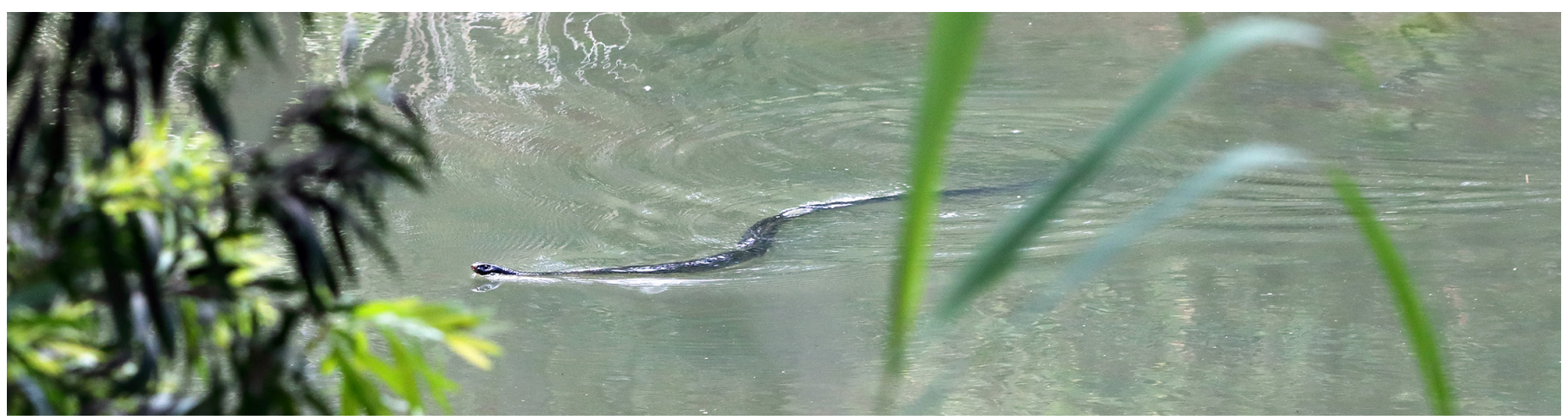

Fig. 1. A Red-bellied Blacksnake (Pseudechis porphyriacus) swimming energetically near the center of a small pond.

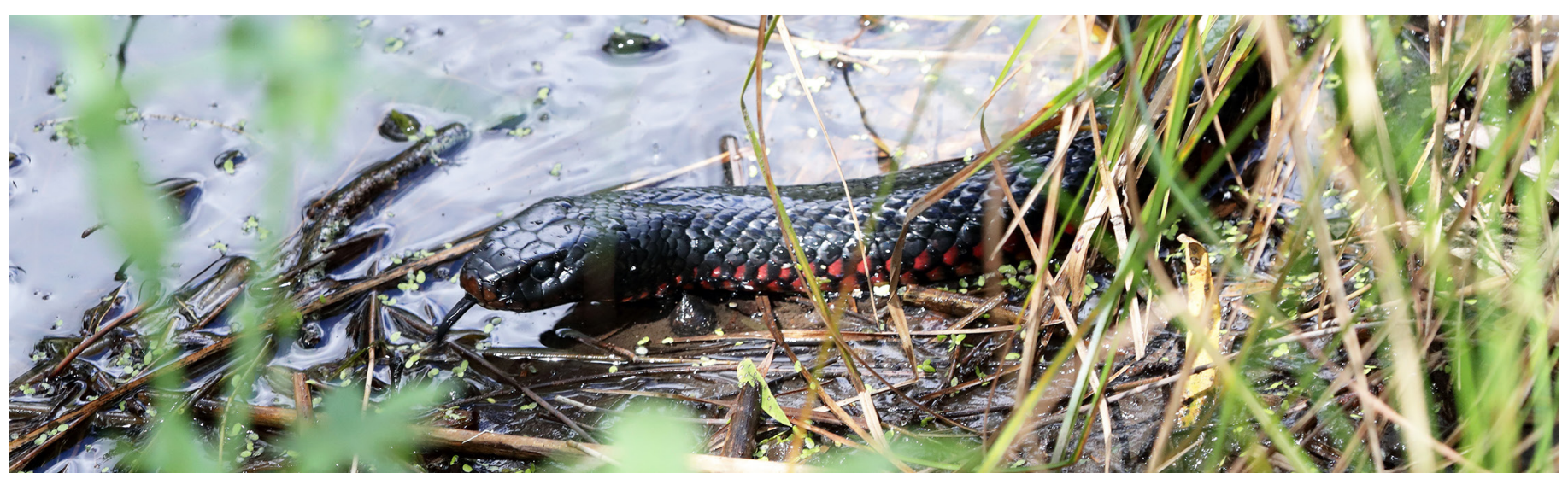

Fig. 2. The Red-bellied Blacksnake (Pseudechis porphyriacus) moving onto the bank. 


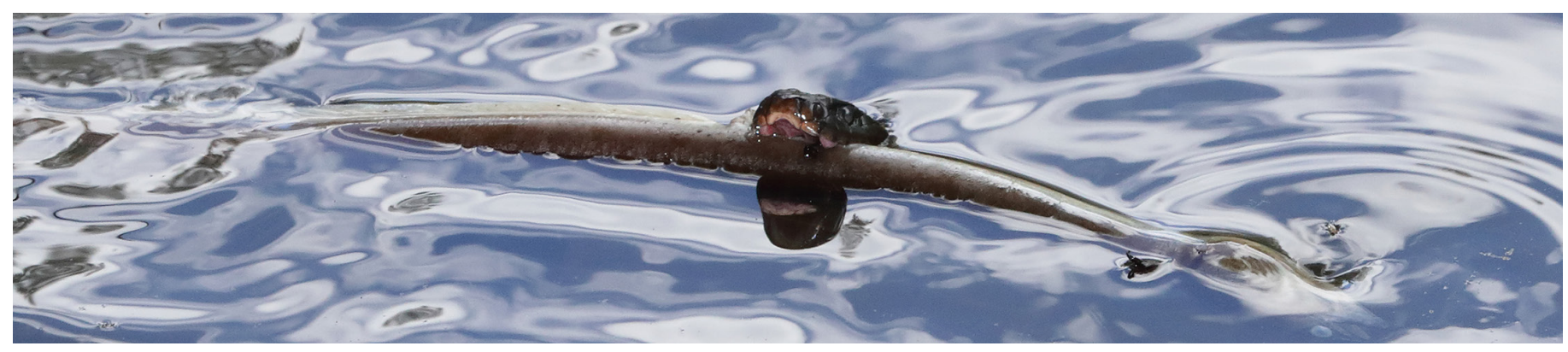

Fig. 3. A Shortfin Eel (Anguilla australis) held by the mid-body before the Red-bellied Blacksnake (Pseudechis porphyriacus) bites it repeatedly.

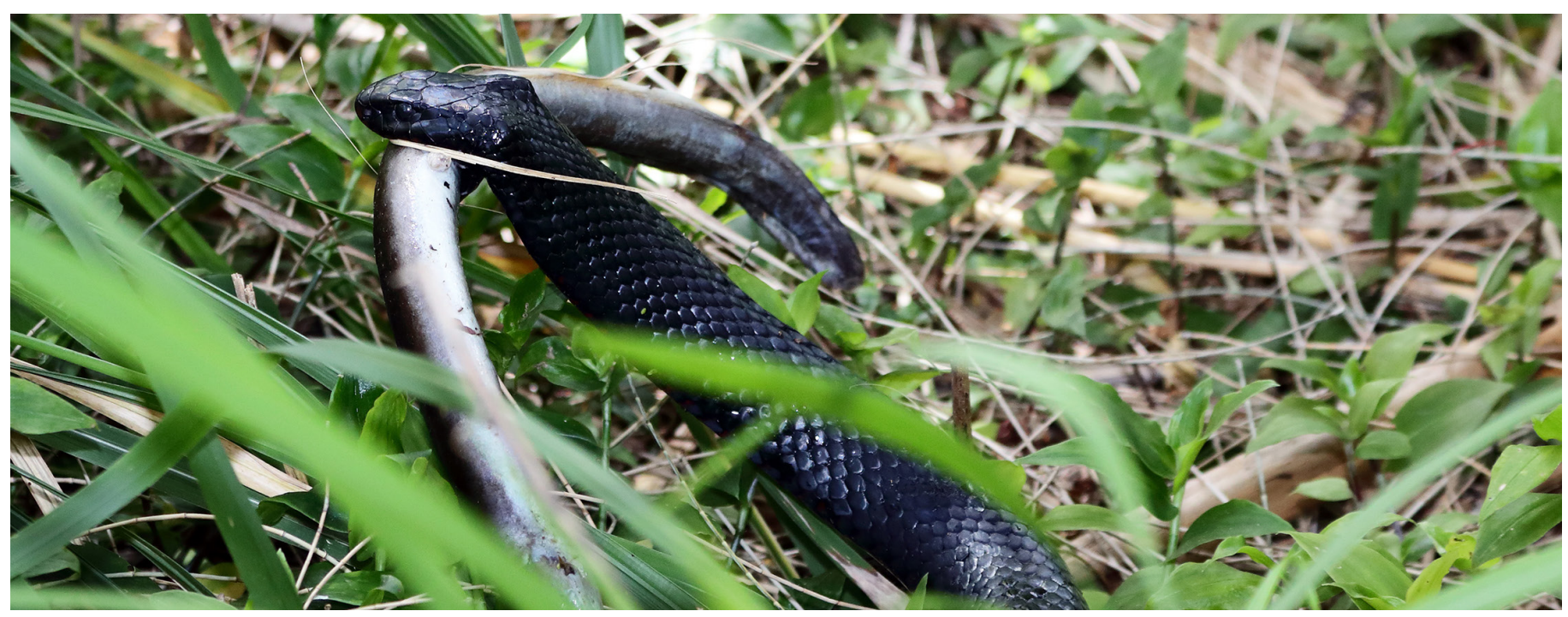

Fig. 4. The Red-bellied Blacksnake (Pseudechis porphyriacus) dragged the dead Shortfin Eel (Anguilla australis) onto the bank to swallow it on land.

Both occurred in the constructed Lime Kiln Bay Wetland in Oatley, New South Wales, Australia. Red-bellied Blacksnakes are frequently encountered at this site (Mo 2015).

At 1540 h on 10 October 2013, we observed a Redbellied Blacksnake extended over a small ephemeral stream. The snake was approximately $1.5 \mathrm{~m}$ long and the amount of water flowing through the creek was a few centimeters deep and no more than $1 \mathrm{~m}$ wide. The snake was stationary for 10 min until a Longfin Eel (Anguilla reinhardtii), approximately $1 \mathrm{~m}$ in length, approached the snake. As the eel passed the snake, the latter bit and held onto the eel behind its head. The eel thrashed briefly before becoming immobile. The snake then released the eel momentarily before moving to the eel's head and swallowing the catch in a few minutes. The snake remained at the site for the remainder of the observation.

At 1025 h on 10 November 2019, we observed another Red-bellied Blacksnake swimming vigorously around the center of a small pond (Fig. 1). This snake was also about $1.5 \mathrm{~m}$ in length. For approximately $5 \mathrm{~min}$, the snake dove and surfaced repeatedly. At one point, a Longfin Eel that was larger than the snake appeared to pursue it, at which time the snake briefly left the water (Fig. 2), possibly to escape the larger eel.
The snake then returned to and continued to hunt in the water and, after one dive, resurfaced holding a $40-\mathrm{cm}$ Shortfin Eel (A. australis) at midbody (Fig. 3). The snake repeatedly bit the eel along its length as it carried it closer to the bank. Once out of the water, the snake dragged its catch under some low vegetation (Fig. 4) and consumed it.

These observations appear to represent two different hunting strategies. In the first instance, the snake was stationary along a shallow creek line where it apparently ambushed the eel (e.g., Olivier et al. 2014) or perhaps made the catch opportunistically. The second observation most likely represented an active foraging attempt, in which the snake moved around the pond searching for prey (e.g., Kojima and Mori 2015). Interestingly, this snake released the eel several times to inflict additional bites. In both observations, the prey was motionless and presumably dead when consumed.

In the second observation, the catch occurred a few minutes after the snake was apparently pursued by a larger Longfin Eel. This might have been inquisitive behavior as the eel's size precluded it from being threatened by the snake. Alternatively, the eel could have been pursuing the snake as a potential prey item. The latter interpretation suggests that the predator-prey relationship between snakes and eels is reciprocal. 


\section{Literature Cited}

Australia Museum. 2019. Red-bellied Black Snake. <https://australianmuseum.net. au/learn/animals/reptiles/red-bellied-black-snake>.

Cogger, H. 2018. Reptiles and Amphibians of Australia. Seventh Edition. CSIRO Publishing, Collingwood, Victoria, Australia.

Kojima, Y. and A. Mori. 2015. Active foraging for toxic prey during gestation in a snake with maternal provisioning of sequestered chemical defences. Proceedings of the Royal Society B 282: 20142137.

Mo, M. 2015. Herpetofaunal community of the constructed Lime Kiln Bay Wetland, south Sydney. Victorian Naturalist 132: 64-72.

Olivier, L., G.E.A. Gartner, and F. Brischoux. 2014. Ambush or active life: Foraging mode influences haematocrit levels in snakes. Biological Journal of the Linnean Society 111: 636-645.
Queensland Museum. 2019. Red-bellied Black Snake Pseudechis porphyriacus. <https://www.qm.qld.gov.au/Find+out+about/Animals+of+Queensland/ Reptiles/Snakes/Common+and+dangerous+species/Redbellied+Black+Snake\#.XfSD72QzY2w>.

Shine, R. 1991. Why do larger snakes eat larger prey items? Functional Ecology 5: 493-502.

University of Melbourne. 2019. Black snakes (Pseudechis spp.). <https://biomedicalsciences.unimelb.edu.au/departments/pharmacology/engage/avru/discover/snakes/dangerous-venomous-snakes-of-major-medical-importance/ black-snakes-pseudechis>.

Victorian Department of Environment, Land, Water and Planning. 2017. Redbellied Black Snake. <https://www.wildlife.vic.gov.au/_data/assets/pdf_ file/0016/84112/Red-bellied-Black-Snake.pdf>.

Wilson, S. and G. Swan. 2017. A Complete Guide to Reptiles of Australia. Fifth Edition. New Holland Publishers, Sydney, New South Wales, Australia. 